\title{
Mechanisms of coronary complications after the arterial switch for transposition of the great arteries
}

\author{
Phalla Ou, MD, PhD, ${ }^{\text {a,b }}$ Diala Khraiche, MD, ${ }^{\mathrm{c}}$ David S. Celermajer, PhD, FRACP, DSc, FAA, ${ }^{\mathrm{d}}$ \\ Gabriella Agnoletti, MD, PhD, ${ }^{\mathrm{c}}$ Kim-Hanh Le Quan Sang, MD, ${ }^{\mathrm{e}}$ Jean Christophe Thalabard, MD, PhD, ${ }^{\mathrm{b}}$ \\ Mathieu Quintin, MS, ${ }^{\mathrm{f}}$ Olivier Raisky, MD, PhD, ${ }^{\mathrm{c}}$ Pascal Vouhe, $\mathrm{MD}, \mathrm{PhD},{ }^{\mathrm{c}}$ Daniel Sidi, MD, PhD, ${ }^{\mathrm{c}}$ \\ and Damien Bonnet, $\mathrm{MD}, \mathrm{PhD}^{\mathrm{c}}$
}

\begin{abstract}
Background: The arterial switch operation (ASO) for transposition of the great arteries requires transfer of the coronary arteries from the aorta to the proximal pulmonary artery (neoaorta). This is complicated by variable coronary anatomy before transfer. In $8 \%$ to $10 \%$ of cases, there is evidence of late coronary stenosis and/or occlusion, often with catastrophic clinical consequences. The mechanism of such complications has not been well studied.

Methods and Results: We analyzed 190 consecutive high-resolution computed tomographic scans from the ASO procedure (patients aged 5-16 years) and found 17 patients with significant ( $>30 \%$ up to occlusion) coronary lesions $(8.9 \%)$; all were later confirmed by conventional angiography. The left main coronary artery was abnormal in 9 patients (ostium in all), the left anterior descending artery in 3, the circumflex in 2 , and the right coronary artery in 3 patients. Using multiplanar and 3-dimensional reconstructions of the coronary arteries, aorta, and pulmonary artery, we identified the commonest mechanisms of coronary abnormalities. For the left main and left anterior descending artery, anterior positioning of the transferred left coronary artery (between 12 and $1 \mathrm{o}$ 'clock on the neoaorta) appeared to predispose to a tangential course of the proximal left coronary artery promoting stenosis. All circumflex lesions occurred in Yacoub type D coronaries where a long initially retroaortic artery was stretched by its new positioning behind an enlarged neoaorta. Right coronary artery lesions occurred only in cases in which the reimplantation site was very high above the right coronary sinus with potential compression from the main pulmonary artery bifurcation immediately above.
\end{abstract}

Conclusions: Thus detailed multiplanar computed tomographic scanning can elucidate the mechanisms of late coronary complications after the ASO. Understanding these aspects could help to improve surgical technique to minimize the risk of late coronary obstructions. (J Thorac Cardiovasc Surg 2013;145:1263-9)

Video clip is available online.

The arterial switch operation (ASO) is the treatment of choice for transposition of the great arteries. ${ }^{1}$ The technique requires transfer of the coronary arteries from the aorta to the proximal pulmonary artery (neoaorta). This is complicated by the variable coronary anatomy before transfer. ${ }^{2}$

\footnotetext{
From Hôpital Necker-Enfants Malades, ${ }^{a}$ AP-HP, University Paris-Descartes, Paris, France; Laboratoire MAP5 - UMR $8145,{ }^{\mathrm{b}}$ University Paris-Descartes, Paris, France; Centre de Référence des Malformations Cardiaques Congénitales Complexes-M3C, ${ }^{\mathrm{c}}$ Hôpital Necker-Enfants Malades, AP-HP, University Paris-Descartes, Paris, France; Department of Medicine, ${ }^{\mathrm{d}}$ Royal Prince Alfred Hospital, University of Sydney, Sydney, Australia; Hôpital Necker-Enfants Malades, ${ }^{\text {e }}$ Clinical Pharmacology, Department of Genetics, AP-HP, University Paris-Descartes, Paris, France; and DRCD,${ }^{f}$ AP-HP, Paris, France.

Disclosures: Authors have nothing to disclose with regard to commercial support.

Received for publication March 15, 2011; revisions received May 11, 2012; accepted for publication June 8, 2012; available ahead of print July 16, 2012.

Address for reprints: Phalla Ou, MD, PhD, Hôpital Necker-Enfants Malades, 149 rue de Sèvres, 75743 Paris Cedex 15, France (E-mail: phalla.ou@nck.aphp.fr). $0022-5223 / \$ 36.00$

Copyright (c) 2013 by The American Association for Thoracic Surgery http://dx.doi.org/10.1016/j.jtcvs.2012.06.009
}

In $8 \%$ to $10 \%$ of cases, there is evidence of late coronary stenosis and/or occlusion, often with serious clinical consequences. ${ }^{3-6}$

Such coronary lesions are somewhat predictable in certain situations, for example, with the intramural course or with Yacoub type B coronary arteries. ${ }^{2}$ However, the mechanism of the complications has not been well explained in the vast majority of cases in which the preoperative coronary pattern is apparently favorable (Yacoub A or D). In these patients, peculiar relationships between the reimplanted coronary arteries and the adjacent great arteries are suspected. ${ }^{6}$ Postoperative modifications and/or spatial rearrangements of the great arteries as children grow may cause complications such as compression, kinking, or stretching that usually involve the ostial and proximal segments. ${ }^{3}$

Multislice computed tomography (CT) has been demonstrated to be a suitable alternative noninvasive method for the detection of coronary complications after ASO. ${ }^{7-9}$ It also provides invaluable data about the 3-dimensional relationships between the coronaries and adjacent great arteries. The aim of our study was to assess the postoperative relationship of the reimplanted coronaries and great arteries with multiplanar and 3-dimensional reconstructions of the 


$$
\begin{aligned}
& \text { Abbreviations and Acronyms } \\
& \begin{aligned}
\text { ASO } & =\text { arterial switch operation } \\
\text { CT } & =\text { computed tomography } \\
\text { LAD } & =\text { left anterior descending artery } \\
\text { LMCA } & =\text { left main coronary artery } \\
\text { MRI } & =\text { magnetic resonance imaging } \\
\text { RCA } & =\text { right coronary artery }
\end{aligned}
\end{aligned}
$$

vessels to better understand the commonest mechanisms of coronary lesions after ASO.

\section{PATIENTS AND METHODS}

At our institution, children surviving the ASO for transposition of the great arteries undergo routine multislice CT for clinical purposes at the age of approximately 5 years. In cases in which CT suggests a coronary abnormality, conventional coronary angiography is performed for confirmation and for assessment of collaterals.

We analyzed 190 consecutive high-resolution CT scans performed from 2005 to 2010 from the ASO procedure. Patients were aged 5 years to 16 years. Exclusion criteria were preoperative intramural course of the coronary arteries.

\section{CT Angiography}

All examinations were performed with a 64-slice CT machine (LightSpeed VCT; GE Medical Systems, Milwaukee, Wis). All patients were in sinus rhythm and, if not contraindicated, received oral beta-blocker medication (propranolol 1-2 mg/kg) 1 hour before CT examination with the aim of lowering resting heart rate to less than 80 beats $/ \mathrm{min}$.

CT scanning was performed with intravenous contrast enhancement, as previously described. ${ }^{8}$ In brief, iodine contrast agent was injected (iohexol $300 \mathrm{mg} / \mathrm{mL}, 1.5$ to $2 \mathrm{~mL} / \mathrm{kg}$, at a rate of $2-3 \mathrm{~mL} / \mathrm{s}$ ) with a power injector, followed by a chaser bolus of 10 to $15 \mathrm{~mL}$ saline into a peripheral vein. The standard CT angiography acquisition was made in a craniocaudal direction, extended from the pulmonary trunk to just below the base of the heart. Retrospective electrocardiogram-gated acquisitions protocol included a 350-ms speed rotation and a collimation of $64 \times 0.625 \mathrm{~mm}$. The CT parameters were adapted to the patient's weight and a fully automated real-time, anatomy-based, dose-regulation algorithm modulated the effective tube current.

A first set of images was reconstructed systematically at $75 \%$ of the R-R interval, with a smooth kernel and mediastinal windows. The entire cardiac cycle was systematically reconstructed from $10 \%$ to $90 \%$ of the R-R interval, with an increment of $10 \%$.

\section{Conventional Coronary Angiography}

Conventional coronary angiography was performed with oral sedation (hydroxyzine, $1 \mathrm{mg} / \mathrm{kg} 1$ hour before the examination, maximum 100 $\mathrm{mg}$ ) and local anesthesia using $4 \mathrm{~F}$ catheters, as previously described. ${ }^{3}$

\footnotetext{
Analysis of CT Data

Great arteries and coronary arteries were analyzed using axial slices and with the aid of postprocessing tools including multiplanar reconstruction, maximum-intensity thin-slab projection, and 3-dimensional reconstruction. Coronary analysis was limited to the ostial and proximal segments. Coronary lesions were stated as significant if greater than $30 \%$ obstruction.

Spatial relationships between the coronaries and the adjacent great arteries (aorta and pulmonary artery) were quantitatively characterized with the use of 2 measurements, called the "coronary angle" and the "coronary-pulmonary bifurcation distance."
}

The coronary angle was determined as follows (Figure 1): On an axial image with maximum intensity projection showing both the coronaries and the great arteries, we determined the center line that passes through the centers of both the pulmonary artery and the aorta. Then, we drew the reference line $\left(0^{\circ}\right)$ that passes through the center of the aorta and that is perpendicular to the aortopulmonary centerline. The coronary angle (expressed in degrees) was given by the measure of the angle between the reference line and the coronary ostia.

The coronary-pulmonary bifurcation distance was determined as follows. The coronary ostia and the center of the pulmonary bifurcation were visualized at the joint native axial images (slice thickness, $0.625 \mathrm{~mm}$ ). The distance $(\mathrm{d}, \mathrm{mm}$ ) separating the 2 levels was calculated as $\mathrm{d}=$ (level of the center of the pulmonary bifurcation-level of the coronary ostium) $\times 0.625$.

\section{Statistical Analysis}

Data were stored and anlayzed using the JMP software version 5.0.1a (SAS Institute, Inc, Cary, NC). Values are expressed as mean \pm standard deviation, range, or median. Differences between the coronary angles and coronary-pulmonary bifurcation were tested by unpaired $t$ tests at the $95 \%$ confidence level (2-tailed).

\section{RESULTS}

We found $17(8.9 \%)$ patients with significant $(>30 \%$ stenosis up to complete occlusion) coronary lesions; all were later confirmed by conventional angiography. The left main coronary artery (LMCA) was abnormal in 9 patients (ostium in all): the left anterior descending artery (LAD) in 3 , the circumflex in 2 , and the right coronary artery (RCA) in 3 patients.

As compared with patients without any coronary abnormality, the 12 patients with lesions involving the LMCA and the LAD had a more anterior reimplantation of the left coronary arteries. The site of reimplantation of the transferred coronaries was between 12 and 1 o'clock on the neoaorta, corresponding to a mean left coronary angle of $87^{\circ} \pm$ $5^{\circ}$ versus $75^{\circ} \pm 8^{\circ}(P=.02)$ (Figure 2$)$. In addition to the anterior positioning, the LAD was also reimplanted too high above the left aortic sinus. The coronary-pulmonary artery bifurcation distance was shorter in the 3 patients with a lesion of the LAD as compared with those without any lesion ( $4.5 \pm 1 \mathrm{~mm}$ vs $7.9 \pm 2 \mathrm{~mm} ; P=.015)$ (Figure 3 ).

All circumflex lesions occurred in Yacoub type D coronaries where a long initially retroaortic artery was stretched by its new positioning behind the neoaorta. The coronary-pulmonary artery bifurcation distance is longer in the 2 patients with a lesion of the circumflex as compared with those without any lesion ( $26 \pm 5.2 \mathrm{~mm}$ vs $16.7 \pm 7 \mathrm{~mm} ; P=.01$ ) (Figure 4).

All RCA lesions occurred in cases in which the reimplantation site was far above the right coronary sinus. The coronary-pulmonary artery bifurcation distance was shorter in the 3 patients with a lesion of the RCA as compared with those without any lesion $(5 \pm 1.5 \mathrm{~mm}$ vs $8.8 \pm 1.7 \mathrm{~mm}$; $P=.03$ ) (Figure 5).

\section{Outcome of Patients With Coronary Obstruction}

One patient with a focal and tight stenosis of left coronary artery ostium underwent successful balloon dilatation. He 

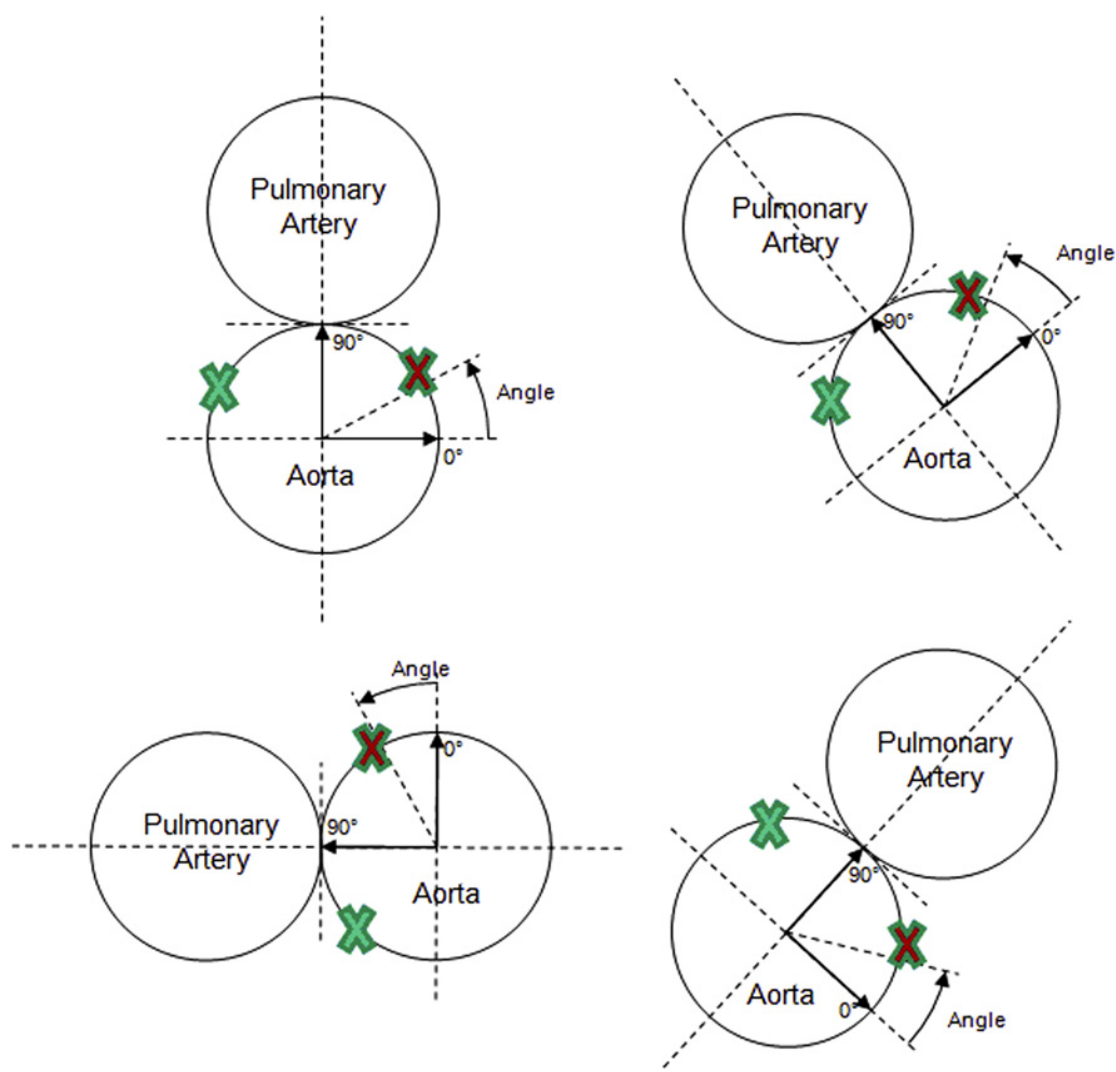

FIGURE 1. Determination of the coronary angles. The commonest positioning of the greats arteries and the coronaries after ASO are representing here. The coronary angles were determined as follows: (1) The aortopulmonary centerline that passes through the center of both the aorta and the pulmonary artery was drawn; (2) the perpendicular of the aortopulmonary centerline that passes through the center of the aorta is the reference line $\left(0^{\circ}\right)$; (3) the angle between the coronary ostia (red cross, left ostium; green cross, right ostium) and the reference line correspond to the coronary angle.

was symptom-free 18 months after the percutaneous procedure, and myocardial scintigraphy showed limited ischemia involving the inferoapical area of the left ventricle.

The other 16 patients with significant coronary obstruction had undergone myocardial perfusion evaluation with myocardial scintigraphy and/or magnetic resonance imaging (MRI) first-pass perfusion with dipyridamole perfusion (intravenous injection of $0.5 \mathrm{mg} / \mathrm{kg}$ during at least $5 \mathrm{~min}$ utes). Extensive ischemia was objectively found in 5 patients with ostial LMCA stenosis, 1 patient with LAD stenosis, and 1 patient with RCA stenosis. Surgical revascularization with coronary angioplasty was successfully performed in these 7 patients. There was no evidence of myocardial ischemia in the other 9 patients with anatomic coronary obstruction (3 LMCA, 2 LAD, 2 circumflex, 2 RCA). Medical treatment with a beta-blocker was proposed as well as a close surveillance with regular check of myocardial perfusion with MRI.

\section{DISCUSSION}

Little is known about the postoperative geometric rearrangement of the great arteries and the coronary arteries after the Lecompte maneuver (part of the ASO procedure) during the development in children as they grow. Using multiplanar and 3-dimensional reconstructions of the coronary arteries, aorta, and pulmonary artery, we show here that the spatial relationships between the great arteries and the reimplanted coronary arteries are related to the risk of coronary obstructions. We currently use CT coronary angiography to screen patients for late coronary obstructions after ASO, and we think that this technique can provide a comprehensive anatomic assessment of the underlying mechanisms of late ischemic complications.

Postoperative coronary obstructions are widely known and predictable in certain complex preoperative coronary patterns, especially in cases of intramural course as in unique coronary artery pattern. ${ }^{2}$ Residual stenosis and intimal proliferation involving a histologically abnormal coronary wall are common in this setting.

In our study, the majority of late coronary lesions (12/17 patients, $70 \%$ ) are surprisingly found in patients with a favorable preoperative coronary pattern, such as Yacoub types $\mathrm{A}$ and $\mathrm{D}$. We found that the anterior positioning of the left coronary artery was the main CT feature in patients 


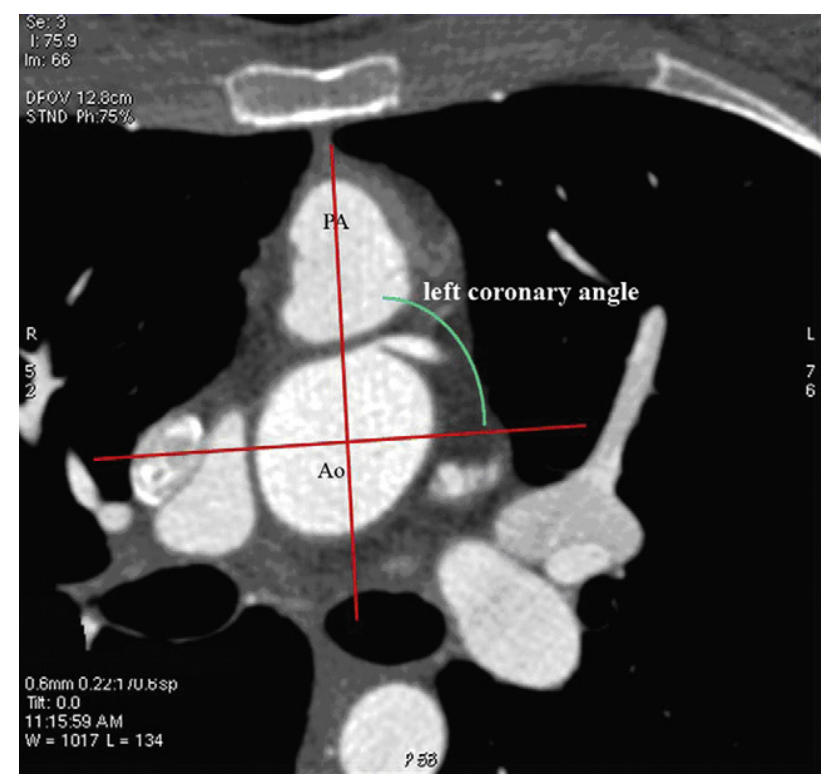

FIGURE 2. Significant stenosis of the ostium of the left coronary artery by anterior compression by the pulmonary artery. The reimplantation is too anterior, as confirmed by the left coronary angle (green curve) almost equal to $90^{\circ}$, corresponding to a reimplantation at 12 o' clock. $P A$, Pulmonary artery; $A o$, aorta.

with obstructed LMCA or LAD. We hypothesized that this anterior position of the left coronary ostium led the proximal part of the left coronary artery to circle around the aorta and potentially to course between the 2 great vessels. This elongated course and potential compression between the 2 great vessels may promote the development of late stenosis. This mechanism is illustrated on axial CT images (Figure 2). In this patient with normal coronary pattern (Yacoub type A), the LMCA was reimplanted anteriorly, between 12 and 1 o'clock on the neoaorta. This anterior positioning of the LMCA ostium may potentially not be present immediately after ASO but be an acquired position owing to growth/enlargement and elongation of the ascending aorta. This might be a cause for late coronary obstruction that is not related to complex congenital coronary patterns. For this reason, practical consequences of this finding on the technique of coronary transfer might be limited. When the LAD was isolated (Yacoub type D), there was a conjunction of 2 mechanisms leading to an obstruction of the LAD. Indeed, the anterior positioning of the transferred LAD was associated with high reimplantation of the ostium above the left aortic sinus. This predisposed the initial course of the LAD to compression by the pulmonary artery. In fact, these 2 mechanisms are not fully different, and we can propose that the cause for proximal stenosis of the coronary artery reimplanted in the left ostium is related to its potential course tangentially to the aorta being in its usual epicardial position with a potential risk to be compressed between the 2 great arteries.

All lesions of the circumflex artery occurred in Yacoub type D patterns where a long initially retroaortic artery was stretched by its new positioning behind an enlarged neoaorta. It must be pointed out that in the physiologic

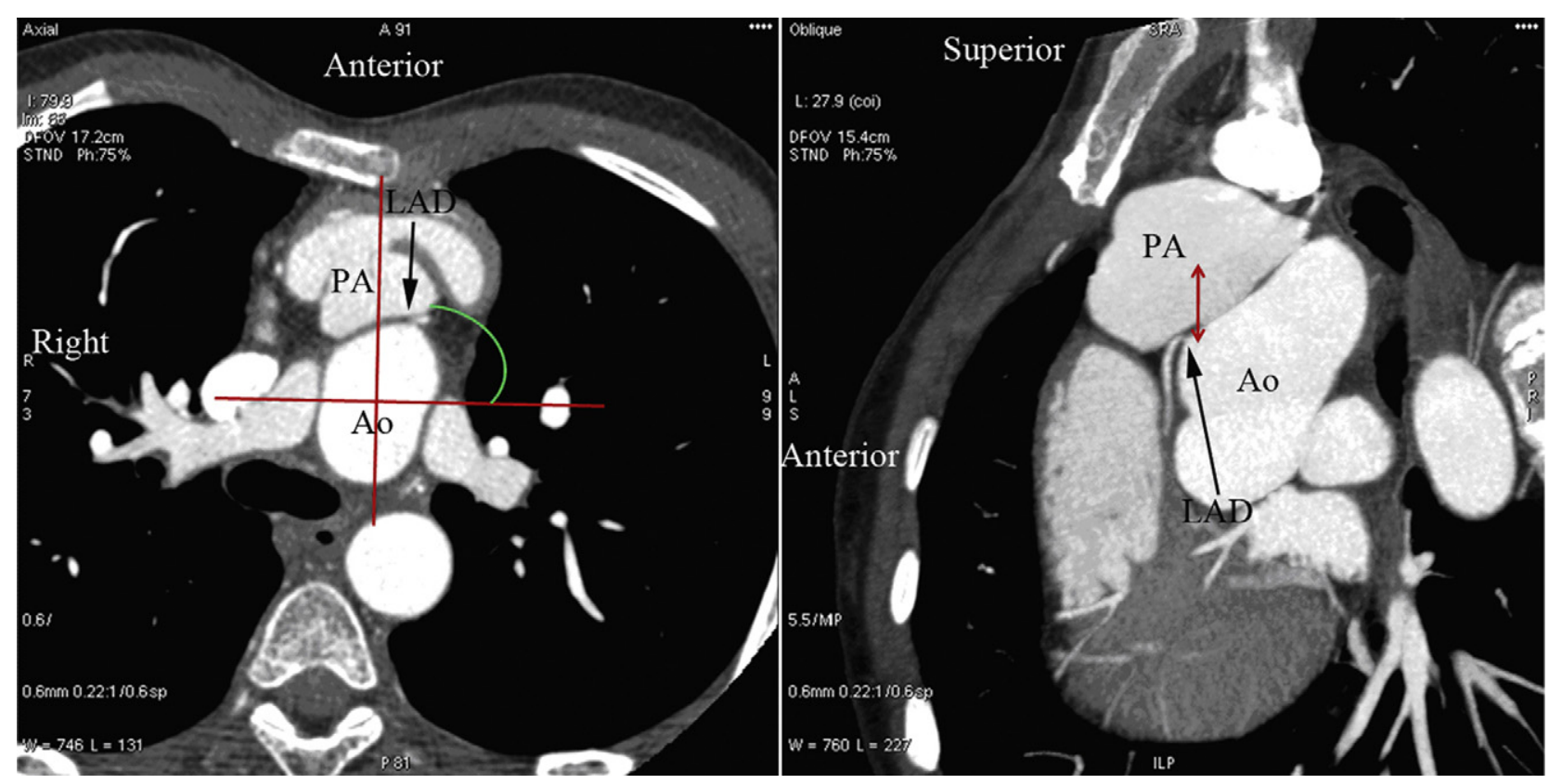

FIGURE 3. Tight stenosis of the LAD in the Yacoub type D. The reimplantation of the LAD (black arrow on the left panel) is to anterior as indicated by the left coronary angle almost equal to $90^{\circ}$ (green curve on the left panel), and also too high above the left coronary sinus, as identified by the short coronarypulmonary bifurcation distance (red arrow on the right panel) equal to $5 \mathrm{~mm}$. PA, Pulmonary artery; Ao, aorta; LAD, left anterior descending artery. 

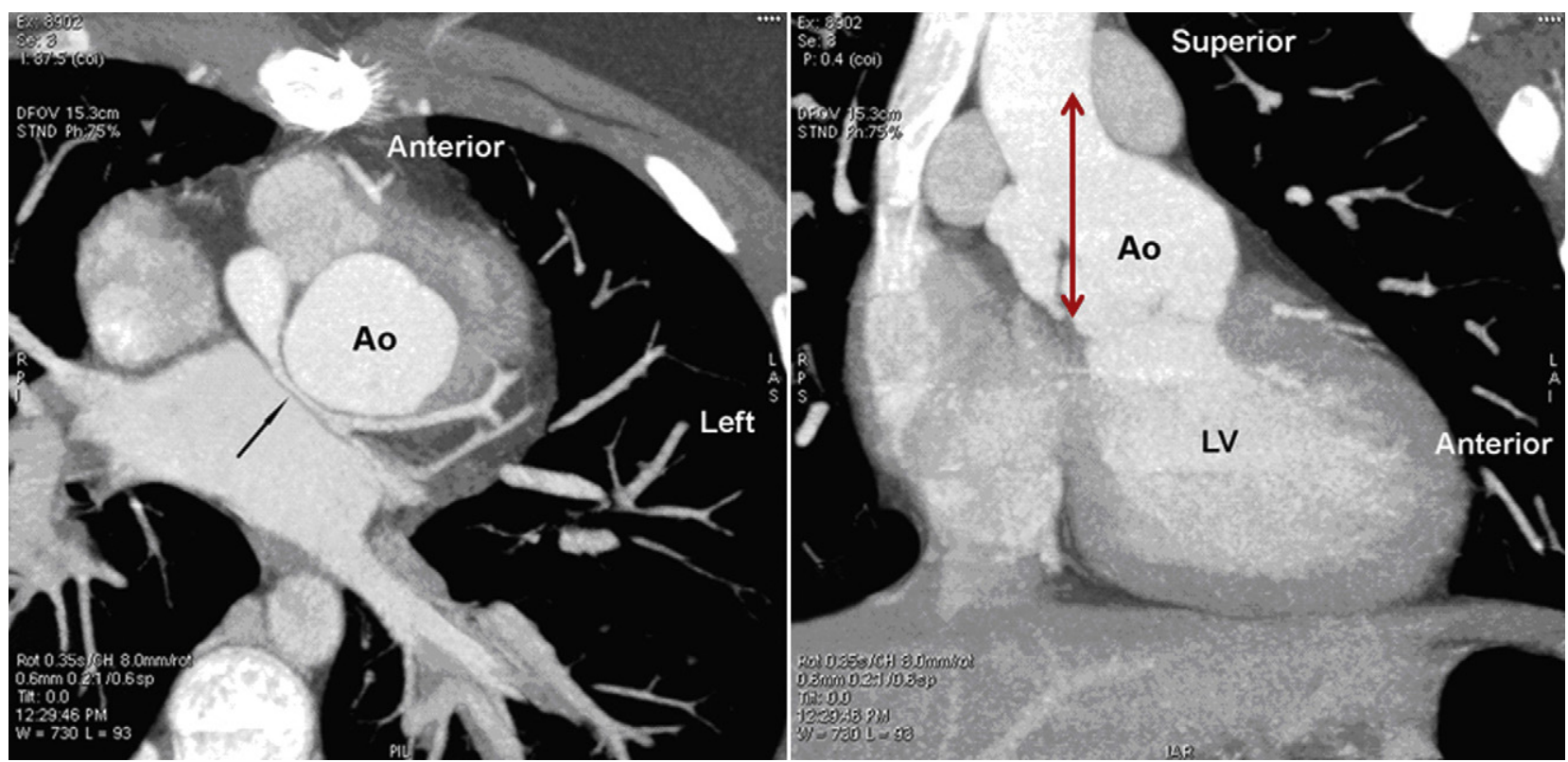

FIGURE 4. Mechanism of lesion of the circumflex artery in Yacoub type D. The reimplantation of the right ostium was too far under the right sinus, as evidenced by the long coronary-pulmonary artery distance (red arrow on the right panel). Thus, the course of the circumflex toward the left atrioventricular groove is increased, causing a stretching of the coronary artery (black arrow on the left panel). Ao, Aorta; $L V$, left ventricle.

situation, the left ostium rises higher from the left aortic sinus as compared with the right ostium in the right aortic sinus. In such normal configuration, the circumflex has a relatively short course for going to the left atrioventricular groove. In the case of a retroaortic course from the right sinus, the length of the circumflex is anatomically increased because of the long loop behind the aorta. A reimplantation of the right sinus far under the right aortic sinus causes a longer retroaortic course for the circumflex in Yacoub type D. This mechanism was found in the 3 patients with a stretching lesion involving the retroaortic segment of the circumflex.

RCA lesions occurred only in cases in which the reimplantation site was very high above the right coronary sinus with potential compression from the main pulmonary artery bifurcation located immediately above.

As post-ASO coronary lesions are probably progressive, our policy is to perform coronary assessment by electrocardiogram-gated $\mathrm{CT}$ in children younger than 8 years old; this has replaced conventional coronary angiography in this setting in our institution. ${ }^{8}$ The timing of the coronary exploration depends on the clinical setting. A CT scan is undertaken early in the postoperative period, in the presence of any echocardiographic finding suggestive of myocardial ischemia. The coronaries are also checked in the first postoperative year in children with complex coronary patterns (intramural course) or in cases of intraoperative difficulties in coronary transfer. Patients with a favorable coronary pattern who had a straightforward intraoperative and postoperative course had a routine coronary CT scan at 5 years old. MRI is certainly the method of choice for assessing the proximal segments of the coronaries but only in cooperative children older than

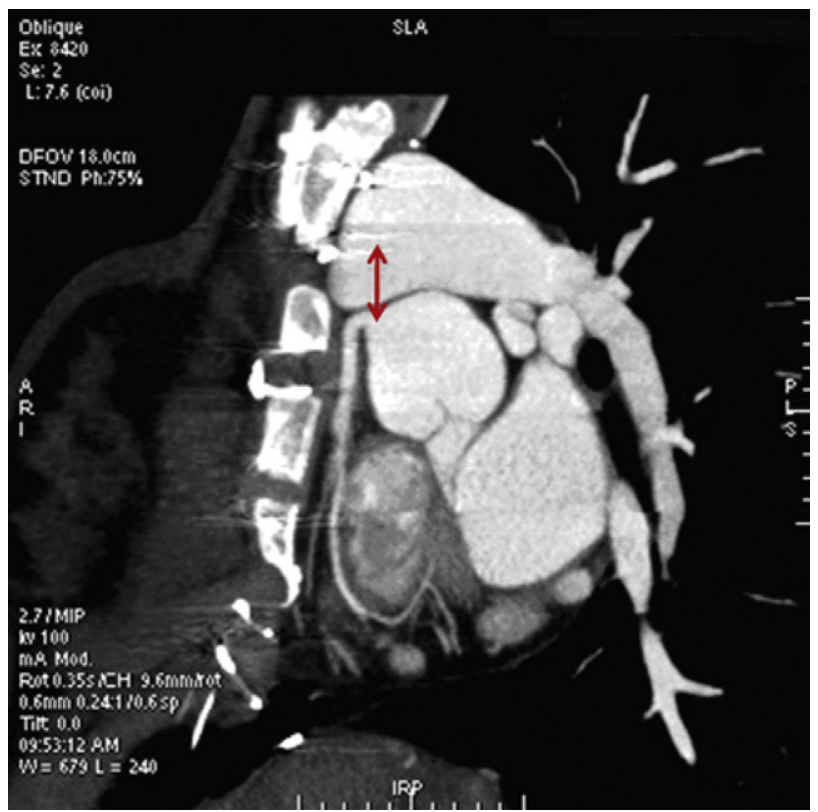

FIGURE 5. Lesion of the right coronary artery. The reimplantation of the right sinus is too high above the right sinus, as evidenced by the short coronary-pulmonary artery bifurcation distance (red arrow). The right ostium was then compressed by the pulmonary artery. This patient had a long "olasty" of the ostium and proximal segment of the right coronary artery using saphenous vein. See the difference in caliber between the saphenous vein in the proximal segment and the native distal segment, which is thinner. 


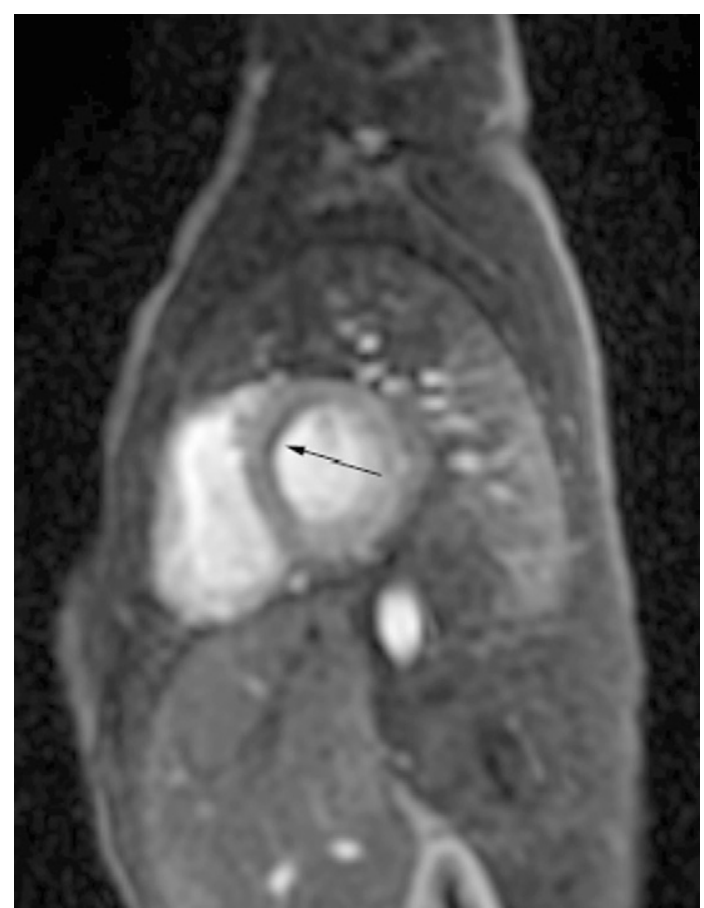

FIGURE 6. Delayed on first-pass perfusion (black arrow, and see Video 1). Magnetic resonance imaging sequence involving the anteroseptobasal segment in a patient with a tight stenosis in the left anterior descending artery (Yacoub type D) owing to a compression by the pulmonary artery. Ischemia was also confirmed on myocardial scintigraphy.

8 years of age. ${ }^{10}$ It can provide both comprehensive anatomic data and functional information regarding the perfusion and viability of the myocardium. ${ }^{11}$

Optimal management of post-ASO coronary lesions remains to be determined. Percutaneous coronary angioplasty seems to provide satisfactory midterm results in suitable cases. ${ }^{12}$ Our current policy is to perform surgical revascularization in patients with any significant coronary lesion and objective evidence of myocardial ischemia, confirmed on myocardial scintigraphy and/or delayed perfusion on MRI at rest and/or with dipyridamole infusion. ${ }^{4,13-15}$ Coronary angioplasty and thoracic artery grafting in selected cases provide satisfactory midterm results. ${ }^{13,16}$ Long-term results, however, still need to be determined. The management of patients without evidence of myocardial ischemia is more questionable. Our current management is to organize surveillance, but this choice has some limitations inasmuch as confirming that myocardial perfusion remains normal for the long term may be problematic. Indeed, the different techniques available to detect myocardial ischemia have their own advantages and limits. Exercise test has a low sensitivity, single photon emission computed tomography should be limited because of radiation, availability of positron emission tomography imaging is highly limited, and stress echocardiography remains a difficult technique in children; its indication is limited to expert centers. ${ }^{17}$ Today, we do not operate on children without any evidence of myocardial ischemia but propose to regularly check myocardial perfusion with MRI during follow-up (Figure 6).

A strength of our study is the inclusion of a large number of children who underwent electrocardiogram-gated CT, thus allowing an exhaustive assessment of the great vessels and their anatomic relationship with the variable coronary pattern after an ASO. Additional experiences and results from other centers should be reported for a better understanding of the coronary complications in this setting. Additional information regarding the evolution of the rearrangement of the coronary arteries and the great vessels as children grow still needs to be elucidated. It is important to evaluate how geometric relationships 5 and more than 10 years after ASO are truly reflective of the geometric relationships that surgeons are confronted with in the operating room. We have concentrated on this question and plan to repeat periodic assessment of the whole heart with using 3-dimensional cardiac MRI of our cohort at 10 and 15 years after ASO.

\section{CONCLUSIONS}

Detailed multiplanar CT scanning can elucidate the mechanisms of late coronary complications after the ASO. Understanding these aspects could help to improve the surgical techniques to minimize the risk of late coronary obstruction. Hitherto, however, we cannot confirm that these anomalies are the direct consequence of a nonoptimal reimplantation of the coronary ostia, a consequence of the changing relationship between the great vessels and the coronary arteries during growth, or a combination of these 2 factors. Consequently, the practical surgical consequences are limited but should take into account these findings to optimize the coronary transfer during the ASO.

\section{References}

1. Yacoub MH, Radley-Smith R. Anatomy of the coronary arteries in transposition of the great arteries and methods for their transfer in anatomical correction. Thorax. 1978;33:418-24.

2. Hutter PA, Bennink GB, Ay L, Raes IB, Hitchcock JF, Meijboom EJ. Influence of coronary anatomy and reimplantation on the long-term outcome of the arterial switch. Eur J Cardiothorac Surg. 2000;18:207-13.

3. Bonnet D, Bonhoeffer P, Piechaud JF, Aggoun Y, Sidi D, Planché C, et al. Longterm fate of the coronary arteries after the arterial switch operation in newborns with transposition of the great arteries. Heart. 1996;76:274-9.

4. Bonhoeffer P, Bonnet D, Piechaud JF, Stumper O, Aggoun Y, Villain E, et al. Coronary artery obstruction after the arterial switch operation for transposition of the great arteries in newborns. J Am Coll Cardiol. 1997;29:202-6.

5. Pasquali SK, Hasselblad V, Li JS, Kong DF, Sanders SP. Coronary artery pattern and outcome of arterial switch operation for transposition of the great arteries: a meta-analysis. Circulation. 2002;106:2575-80.

6. Legendre A, Losay J, Touchot-Kone A, Serraf A, Belli E, Piot JD, et al. Coronary events after arterial switch operation for transposition of the great arteries. Circulation. 2003;108(Suppl 1):II186-90.

7. Ou P, Mousseaux E, Azarine A, Dupont P, Agnoletti G, Vouhé P, et al. Detection of coronary complications after the arterial switch operation for transposition of the great arteries: first experience with multislice computed tomography in children. J Thorac Cardiovasc Surg. 2006;131:639-43.

8. Ou P, Celermajer DS, Marini D, Agnoletti G, Vouhé P, Brunelle F, et al. Safety and accuracy of 64-slice computed tomography coronary angiography in 
children after the arterial switch operation for transposition of the great arteries. JACC Cardiovasc Imaging. 2008;1:331-9.

9. Oztunç F, Bariş S, Adaletli I, Onol NO, Olgun DC, Güzeltaş A, et al. Coronary events and anatomy after arterial switch operation for transposition of the great arteries: detection by 16-row multislice computed tomography angiography in pediatric patients. Cardiovasc Intervent Radiol. 2009;32: 206-12.

10. Taylor AM, Dymarkowski S, Hamaekers P, Razavi R, Gewillig M, Mertens L, et al. MR coronary angiography and late-enhancement myocardial MR in children who underwent arterial switch surgery for transposition of great arteries. $R a$ diology. 2005;234:542-7.

11. Manso B, Castellote A, Dos L, Casaldáliga J. Myocardial perfusion magnetic resonance imaging for detecting coronary function anomalies in asymptomatic paediatric patients with a previous arterial switch operation for the transposition of great arteries. Cardiol Young. 2010;20:410-7.

12. Kampmann C, Kuroczynski W, Trübel H, Knuf M, Schneider M, Heinemann MK. Late results after PTCA for coronary stenosis after the arterial switch procedure for transposition of the great arteries. Ann Thorac Surg. 2005 80:1641-6.

13. Raisky O, Bergoend E, Agnoletti G, Ou P, Bonnet D, Sidi D, et al. Late coronary artery lesions after neonatal arterial switch operation: results of surgical coronary revascularization. Eur J Cardiothorac Surg. 2007;31:894-8.

14. Bonnet D, Bonhoeffer P, Sidi D, Kachaner J, Acar P, Villain E, et al. Surgical angioplasty of the main coronary arteries in children. $J$ Thorac Cardiovasc Surg. 1999;117:352-7.

15. Metton O, Calvaruso D, Gaudin R, Mussa S, Raisky O, Bonnet D, et al. Intramural coronary arteries and outcome of neonatal arterial switch operation. Eur J Cardiothorac Surg. 2010;37:1246-53.

16. Legendre A, Chantepie A, Belli E, Vouhé PR, Neville P, Dulac Y, et al. Outcome of coronary artery bypass grafting performed in young children. J Thorac Cardiovasc Surg. 2010;139:349-53.

17. Chen MH, Abernathey E, Lunze F, Colan SD, O’Neill S, Bergersen L, et al. Utility of exercise stress echocardiography in pediatric cardiac transplant recipients: a single-center experience. J Heart Lung Transplant. 2012;31:517-23. 